\title{
CHARACTERIZATIONS OF SOME NEAR-CONTINUOUS FUNCTIONS AND NEAR-OPEN FUNCTIONS
}

\author{
C.W. BAKER \\ Department of Matuematics \\ Indiana University Southeast \\ New Albany, Indiana 47150 \\ (Received April 7, 1986)
}

ABSTRACT. A subset $\mathrm{N}$ of a topological space is defined to be a $\theta$-neighborhood of $x$ if there exists an open set $U$ such that $x \varepsilon U \subseteq C 1 U \subseteq N$. This concept is used to characterize the following types of functions: weakly continuous, $\theta$-continuous, strongly $\theta$-continuous, almost strongly $\theta$-continuous, weakly $\delta$-continuous, weakly open and almost open functions. Additional characterizations are given for weakly $\delta$-continuous functions. The concept of $\theta$-neighborhood is also used to define the following types of open maps: $\theta$-open, strongly $\theta$-open, almost strongly $\theta$-open, and weakly $\delta$-open functions.

KEY WORDS AND PHRASES. $\theta$-neighborhood, weakly continuous function, $\theta$-continuous function, strongly $\theta$-continuous function, almost strongly $\theta$-continuous function, weakly

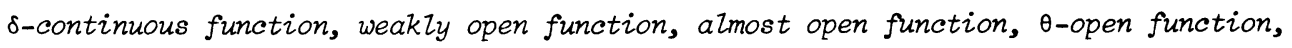
strongly $\theta$-open function, almost strongly $\theta$-open function, weakly $\delta$-open function. 1980 AMS SUBJECT CLASSIFICATION CODE. 54 C10.

\section{INTRODUCTION.}

Near-continuity has been investigated by many authors including Levine [1], Long and Herrington [2], Noiri [3], and Rose [4]. Near-openness has been developed by Rose [5] and Singal and Singal [6]. The purpose of this note is to characterize several types of near-continuity and near-openness in terms of the concept of $\theta$ neighborhood. These characterizations clarify both the nature of these functions and the relationships among them. Additional characterizations of weak $\delta$-continuity are given. The concept of $\theta$-neighborhood also leads to the definition of several new types of near-open functions.

2. DEFINITIONS AND NOTATION.

The symbols $\mathrm{X}$ and $\mathrm{Y}$ denote topological spaces with no separation axioms assumed unless explicitly stated. Let $U$ be a subset of a space $X$. The closure of $U$ and the interior of $U$ are denoted by $C 1 U$ and Int $U$ respectively. The set $U$ is said to be regular open (regular closed) if $U=$ Int $C 1 U$ ( $U=C 1$ Int $U$ ). The $\theta$-closure ( $\delta$-closure) (Velicko [7]) of $U$ is the set of all $x$ in $X$ such that every closed neighborhood (the interior of every closed neighborhood) of $x$ intersects 
$\mathrm{U}$. The $\theta$-ciosure and the $\delta$-closure of $\mathrm{U}$ are denoted by $\mathrm{C} 1_{\theta} \mathrm{U}$ and $\mathrm{C} 1_{\delta} \mathrm{U}$ respectively. The set $U$ is called $\theta$-closed $\left(\delta\right.$-closed) if $U=C 1_{\theta} U\left(U=C 1_{\delta} U\right)$. A set is said to be $\theta$-open ( $\delta$-open) if its complement is $\theta$-closed ( $\delta$-closed). For a given space $X$ the collection of all $\theta$-open sets and the collection of all $\delta$-open sets both form topologies. The space $X$ with the $\theta$-open ( $\delta$-open) topology will be signified by $\mathrm{x}_{\theta}\left(\mathrm{x}_{\mathrm{s}}\right)$.

DEFINITION 1, A function $\mathrm{f}: \mathrm{X} \rightarrow \mathrm{Y}$ is said to be weakly continuous (Levine [1]) ( $\theta$-continuous (Fomin [8]), strongly $\theta$-continuous (Long and Herrington [2]), almost strongly $\theta$-continuous (Noiri and Kang [9]), weakly $\delta$-continuous (Baker [10])) if for each $x \in X$ and each open neighborhood $V$ of $f(x)$, there exists an open neighborhood $U$ of $x$ such that $f(U) \subseteq C 1 V(f(C 1 U) \subseteq C 1 V, f(C 1 U) \subseteq V, f(C 1 U) \subseteq$ Int $\mathrm{Cl} \mathrm{V}, \mathrm{f}($ Int $\mathrm{Cl} \mathrm{U}) \subseteq \mathrm{Cl} \mathrm{V})$.

DEFINITION 2. A function $f: X \rightarrow Y$ is said to be weakly open (Rose [5]) (almost open (Rose [5])) provided that for each open subset $U$ of $X, f(U) \subseteq$ Int $\mathrm{f}(\mathrm{Cl} \mathrm{U}) \quad(\mathrm{f}(\mathrm{U}) \subseteq$ Int $\mathrm{Cl} f(\mathrm{U}))$.

DEFINITION 3. A subset $N$ of a space $X$ is said to be a $\theta$-neighborhood ( $\delta-$ neighborhood) of a point $x$ in $X$ if there exists an open set $U$ such that $x \varepsilon U \subseteq$ $\mathrm{C} 1 \mathrm{U} \subseteq \mathrm{N}(\mathrm{x} \varepsilon \mathrm{E} \subseteq$ Int $\mathrm{C} 1 \mathrm{U} \equiv \mathrm{N})$.

Note that a $\theta$-neighborhood is not necessarily a neighborhood in the $\theta$-topology, but a $\delta$-neighborhood is a neighborhood in the $\delta$-topology.

3. NEAR-CONTINUOUS FUNCTIONS.

The main results can be paraphrased as follows: weak continuity corresponds to "f $f^{-1}(\theta$-neighborhood $)=$ neighborhood"; $\theta$-continuity corresponds to " $f^{-1}(\theta-$ neighborhood) $=\theta$-neighborhood"; strong $\theta$-continuity corresponds to "f ${ }^{-1}$ (neighborhood) $=\theta$-neighborhood"; almost strong $\theta$-continuity corresponds to "F ${ }^{-1}$ ( $\delta$-neighborhood) $=\theta$-neighborhood", and weak $\delta$-continuity corresponds to " $f^{-1}(\theta$-neighborhood $)=$ $\delta$-neighborhood".

THEOREM 1. A function $\mathrm{f}: \mathrm{X} \rightarrow \mathrm{Y}$ is weakly continuous if and only if for each $x$ in $X$ and each $\theta$-neighborhood $N$ of $f(x), f^{-1}(N)$ is a neighborhood of $x$. PROOF. Assume $f$ is weakly continuous. Let $x \in X$ and let $N$ be $a$ neighborhood of $f(x)$. Then there exists an open set $V$ such that $f(x) \varepsilon V \subseteq C l V$ $\subseteq N$. Since $f$ is weakly continuous, there exists an open neighborhood $U$ of $x$ such that $f(U) \subseteq C 1 V \subseteq N$. Thus $x \in U \subseteq f^{-1}(N)$ and hence $f^{-1}(N)$ is a neighborhood of $x$.

Assume for each $\mathrm{x} \varepsilon \mathrm{X}$ and each $\theta$-neighborhood $N$ of $\mathrm{x}$ that $\mathrm{f}^{-1}(\mathrm{~N})$ is a neighborhood of $x$. Let $x \in X$ and let $V$ be an open neighborhood of $f(x)$. Since $\mathrm{C} 1 \mathrm{~V}$ is a $\theta$-neighborhood of $\mathrm{f}(\mathrm{x}), \mathrm{f}^{-1}(\mathrm{Cl} \mathrm{V})$ is a neighborhood of $x$. Thus there is an open set $U$ for which $x \in U \subseteq \mathrm{f}^{-1}(\mathrm{C} 1 \mathrm{~V})$ and $\mathrm{f}(\mathrm{U}) \subseteq \mathrm{Cl} 1 \mathrm{~V}$ which proves $\mathrm{f}$ is weakly continuous.

THEOREM 2. A function $\mathrm{f}: \mathrm{X} \rightarrow \mathrm{Y}$ is $\theta$-continuous if and only if for each $x$ in $X$ and each $\theta$-neighborhood $N$ of $f(x), f^{-1}(N)$ is a $\theta$-neighborhood of $x$. 
PROOF. Assume $\mathrm{f}: \mathrm{X} \rightarrow \mathrm{Y}$ is $\theta$-continuous. Let $\mathrm{x} \varepsilon \mathrm{X}$ and let $\mathrm{N}$ be a $\theta$ neighborhood of $f(x)$. Then there exists an open set $V$ for which $f(x) \varepsilon V \subseteq C l V \subseteq$ N. By the $\theta$-continuity of $f$, there exists an open neighborhood $U$ of $x$ such th. $t$ $\mathrm{f}(\mathrm{Cl} \mathrm{U}) \subseteq \mathrm{Cl} \mathrm{V} \subseteq \mathrm{N}$. Thus $\mathrm{x} \varepsilon \mathrm{U} \subseteq \mathrm{Cl} \mathrm{U} \subseteq \mathrm{f}^{-1}(\mathrm{~N})$ and hence $\mathrm{f}^{-1}(\mathrm{~N})$ is a $\theta-$ neighborhood of $x$.

Assume for each $x$ in $X$ and for each $\theta$-neighborhood $N$ of $f(x)$ that $f^{-1}(N)$ is a $\theta$-neighborhood of $x$. Let $x \varepsilon X$ and let $V$ be an open neighborhood of $f(x)$. Since $C 1 V$ is a $\theta$-neighborhood of $f(x), f^{-1}(C 1 V)$ is a $\theta$-neighborhood of $x$. Hence there exists an open set $U$ for which $x \in U \subseteq C 1 U \subseteq \mathrm{f}^{-1}(C 1 V)$. That is, $\mathrm{f}(\mathrm{C} 1 \mathrm{U}) \subseteq \mathrm{C} 1 \mathrm{~V}$ and thus $\mathrm{f}$ is $\theta$-continuous.

The proof of the following theorem is similar to that of Theorem 2 and is omitted. THEOREM 3. A function $\mathrm{f}: \mathrm{X} \rightarrow \mathrm{Y}$ is strongly $\theta$-continuous if and only if for each $x$ in $X$ and each neighborhood $N$ of $f(x), f^{-1}(N)$ is a $\theta$-neighborhood of $x$. THEOREM 4. A funciton $\mathrm{f}: \mathrm{X} \rightarrow \mathrm{Y}$ is almost strongly $\theta$-continuous if and only if for each $x$ in $x$ and each $\delta$-neighborhood $N$ of $f(x), f^{-1}(N)$ is a $\theta$-neighborhood of $x$.

PROOF. Assume $\mathrm{f}: \mathrm{X} \rightarrow \mathrm{Y}$ is almost strongly $\theta$-continuous. Let $\mathrm{x} \varepsilon \mathrm{X}$ and let $N$ be a $\delta$-neighborhood of $f(x)$. Then there exists an open set $V$ such that $\mathrm{f}(\mathrm{x}) \varepsilon \mathrm{V} \subseteq$ Int $\mathrm{C} 1 \mathrm{~V} \subseteq \mathrm{N}$. Since $\mathrm{f}$ is almost strongly $\theta$-continuous, there exists an open neighborhood $U$ of $x$ for which $f(C 1 U) \subseteq$ Int $C 1 V \subseteq N$. Then $x \varepsilon U \subseteq C 1 U$ $\subseteq \mathrm{f}^{-1}(\mathrm{~N})$ which proves that $\mathrm{f}^{-1}(\mathrm{~N})$ is a $\theta$-neighborhood of $\mathrm{x}$.

Assume for each $x \in X$ and each $\delta$-neighborhood $N$ of $f(x)$ that $f^{-1}(N)$ is a $\theta$-neighborhood of $x$. Let $x \in X$ and let $V$ be an open neighborhood of $f(x)$. Since Int $\mathrm{C} 1 \mathrm{~V}$ is a $\delta$-neighborhood of $\mathrm{f}(\mathrm{x}), \mathrm{f}^{-1}$ (Int $\mathrm{Cl} \mathrm{V}$ ) is a $\theta$-neighborhood of $\mathrm{x}$. Hence there is an open set $U$ such that $x \in U \subseteq C l U \subseteq f^{-1}$ (Int $C 1 V$ ). That is, $\mathrm{f}(\mathrm{Cl} \mathrm{U}) \subseteq$ Int $\mathrm{Cl} \mathrm{V}$ and hence $\mathrm{f}$ is almost strongly $\theta$-continuous.

THEOREM 5. A function $\mathrm{f}: \mathrm{X} \rightarrow \mathrm{Y}$ is weakly $\delta$-continuous if and only if for each $x \in X$ and each $\theta$-neighborhood $N$ of $f(x), f^{-1}(N)$ is a $\delta$-neighborhood of $x$.

The proof of this theorem is similar to that of Theorem 4. The following theorem gives additional characterizations of weak $\delta$-continuity. These results are analogous to those obtained by Noiri and Kang in [9] for almost strongly $\theta$-continuous functions.

LEMMA. Let $X$ be a space and $H \subseteq X$. Then

(a) $\mathrm{Cl}_{\theta} \mathrm{H}=\{\mathrm{x} \varepsilon \mathrm{X}$ : every $\theta$-neighborhood of $\mathrm{x}$ intersects $\mathrm{H}\}$ and
(b) $\mathrm{C} 1_{\delta} \mathrm{H}=\{\mathrm{x} \varepsilon \mathrm{X}$ : every $\delta$-neighobrhood of $\mathrm{x}$ intersects $\mathrm{H}\}$.

The proof follows easily from the definitions.

THEOREM 6. For $\mathrm{f}: \mathrm{X} \rightarrow \mathrm{Y}$ the following statements are equivalent:
(a) $\mathrm{f}: \mathrm{X} \rightarrow \mathrm{Y}$ is weakly $\delta$-continuous.
(b) For each $\mathrm{H} \subseteq \mathrm{X}, \mathrm{f}\left(\mathrm{Cl}_{\delta} \mathrm{H}\right) \subseteq \mathrm{Cl}_{\theta} \mathrm{f}(\mathrm{H})$.
(c) For each $\mathrm{K} \subseteq \mathrm{Y}, \mathrm{C} 1_{\delta} \mathrm{f}^{-1}(\mathrm{~K}) \subseteq \mathrm{f}^{-1}\left(\mathrm{C} 1_{\theta} \mathrm{K}\right)$.
(d) $\mathrm{f}: \mathrm{X}_{\mathrm{s}} \rightarrow \mathrm{Y}$ is weakly continuous. 
PROOF. (a) $\Rightarrow(\mathrm{b})$. Let $\mathrm{H} \subseteq \mathrm{X}$ and let $\mathrm{y} \in \mathrm{f}\left(\mathrm{C} 1_{\delta} \mathrm{H}\right)$. Then there exists an $\mathrm{x}$ in $\mathrm{Cl}_{\delta} \mathrm{H}$ such that $\mathrm{y}=\mathrm{f}(\mathrm{x})$. Let $\mathrm{N}$ be a $\theta$-neighborhood of $\mathrm{f}(\mathrm{x})$. By Theorem 5 $\mathrm{f}^{-1}(\mathrm{~N})$ is a $\delta$-neighborhood of $\mathrm{x}$. Since $\mathrm{x} \varepsilon \mathrm{Cl} 1_{\delta} \mathrm{H}, \mathrm{f}^{-1}(\mathrm{~N}) \cap \mathrm{H} \neq \phi$. That is, $\mathrm{N} \cap \mathrm{f}(\mathrm{H}) \neq \phi$. Hence y $\varepsilon \mathrm{C} 1_{\theta} \mathrm{f}(\mathrm{H})$. Thus $\mathrm{f}\left(\mathrm{C} \cdot 1_{\delta} \mathrm{H}\right) \subseteq \mathrm{Cl}_{\theta} \mathrm{f}(\mathrm{H})$. (b) $\Rightarrow$ (c). Let $\mathrm{K} \subseteq \mathrm{Y}$. By (b) $\mathrm{f}\left(\mathrm{Cl} 1_{\delta} \mathrm{f}^{-1}(\mathrm{~K})\right) \subseteq \mathrm{Cl}_{\theta} \mathrm{f}\left(\mathrm{f}^{-1}(\mathrm{~K})\right) \subseteq \mathrm{C} 1_{\theta} \mathrm{K}$. Thus $\mathrm{C} 1_{\delta} \mathrm{f}^{-1}(\mathrm{~K}) \subseteq \mathrm{f}^{-1}\left(\mathrm{C} 1_{\theta} \mathrm{K}\right)$.

(c) $\Rightarrow(\mathrm{d})$. Let $\mathrm{X} \varepsilon \mathrm{X}$ and let $\mathrm{V}$ be an open neighborhood of $\mathrm{f}(\mathrm{x})$. Since $\mathrm{C} 1 \mathrm{~V}$ is a $\theta$-neighborhood of $\mathrm{f}(\mathrm{x}), \mathrm{f}(\mathrm{x}) \notin \mathrm{Cl}_{\theta} \quad(\mathrm{Y}-\mathrm{Cl} \mathrm{V})$. Hence $\mathrm{x} \notin \mathrm{f}^{-1}\left(\mathrm{Cl} 1_{\theta}(\mathrm{Y}-\mathrm{Cl} \mathrm{V})\right.$. By (c) $\mathrm{x} \notin \mathrm{Cl}_{\delta} \mathrm{f}^{-1}(\mathrm{Y}-\mathrm{Cl} \mathrm{V})$. Thus there is a neighborhood $\mathrm{U}$ of $\mathrm{x}$ such that (Int $\mathrm{C} 1 \mathrm{U}) \cap \mathrm{f}^{-1}(\mathrm{Y}-\mathrm{C} 1 \mathrm{~V})=\phi$. Then $\mathrm{f}($ Int $\mathrm{C} 1 \mathrm{U}) \subseteq \mathrm{Cl}$. Since Int $\mathrm{C} 1 \mathrm{U}$ is a regular open, $\mathrm{f}: \mathrm{X}_{\mathrm{S}} \rightarrow \mathrm{Y}$ is weakly continuous.

$(d) \Rightarrow(a)$. Let $x \in X$ and let $V$ be an open neighborhood of $f(x)$. Since $f$ : $\mathrm{X}_{\mathrm{S}} \rightarrow \mathrm{Y}$ is weakly continuous, there exists a $\delta$-open set $W$ containing $\mathrm{X}$ such that $\mathrm{f}(\mathrm{W}) \subseteq \mathrm{Cl}$ V. Then there is a regular open set $\mathrm{U}$ for which $\mathrm{x} \varepsilon \mathrm{U} \subseteq \mathrm{W}$. Then $\mathrm{f}($ Int $\mathrm{Cl} U)=\mathrm{f}(\mathrm{U}) \subseteq \mathrm{f}(\mathrm{W}) \subseteq \mathrm{Cl} \mathrm{V}$ and hence $\mathrm{f}$ is weakly $\delta$-continuous.

4. NEAR-OPEN FUNCTIONS.

In this section weak openness and almost openness are characterized in terms of the concept of $\theta$-neighborhood.

THEOREM 7. A function $\mathrm{f}: \mathrm{X} \rightarrow \mathrm{Y}$ is weakly open if and only if for each $\mathrm{x} \varepsilon \mathrm{X}$ and each $\theta$-neighborhood $N$ of $x, f(N)$ is a neighborhood of $f(x)$.

PROOF. Assume $\mathrm{f}$ is weakly open. Let $\mathrm{x} \varepsilon \mathrm{X}$ and let $\mathrm{N}$ be a $\theta$-neighborhood of $x$. Then there is an open set $U$ such that $x \varepsilon U \subseteq C 1 U \subseteq N$. Since $f$ is weak$1 y$ open $f(x) \varepsilon f(U) \subseteq$ Int $f(C l U) \subseteq$ Int $f(N)$. Hence $f(N)$ is a neighborhood of $f(x)$. Assume for each $x$ in $X$ and each $\theta$-neighborhood $N$ of $x$ that $f(N)$ is a neighborhood of $f(x)$. Let $U$ be an open set in $X$. Suppose $x \in U$. Since $C 1 U$ is a $\theta$-neighborhood of $x, f(C 1 U)$ is a neighborhood of $f(x)$. Hence $f(x) \varepsilon$ Int $\mathrm{f}(\mathrm{Cl} \mathrm{U})$. Thus $\mathrm{f}(\mathrm{U}) \subseteq$ Int $\mathrm{f}(\mathrm{Cl} U)$ and $\mathrm{f}$ is weakly open.

The proof of the following theorem is similar and is omitted.

THEOREM 8. A function $\mathrm{f}: \mathrm{X} \rightarrow \mathrm{Y}$ is almost open if and only if for each $\mathrm{x} \varepsilon \mathrm{X}$ and each neighborhood $\mathrm{N}$ of $\mathrm{x}, \mathrm{Cl} f(\mathrm{~N})$ is a $\theta$-neighborhood of $\mathrm{f}(\mathrm{x})$.

Theorem 7 and the characterizations of near-continuous functions in Section 3 suggest the following definitions of near-open functions.

DEFINITION 4. A function $\mathrm{f}: \mathrm{X} \rightarrow \mathrm{Y}$ is said to be $\theta$-open (strongly $\theta$-open, almost strongly $\theta$-open, weakly $\delta$-open) if for each $x \in X$ and each $\theta$-neighborhood (neighborhood, $\delta$-neighborhood, $\theta$-neighborhood) $N$ of $x, f(N)$ is a $\theta$-neighborhood ( $\theta$-neighborhood, $\theta$-neighboehood, $\delta$-neighborhood) of $f(x)$.

The following theorems characterize these near-open functions in terms of the closure and interior operators. Since the proofs are all similar, only the first theorem is proved.

THEOREM 9. A function $\mathrm{f}: \mathrm{X} \rightarrow \mathrm{Y}$ is $\theta$-open if and only if for each $\mathrm{X} \varepsilon \mathrm{X}$ and each open neighborhood $U$ of $x$, there exists an open neighborhood $V$ of $f(x)$ such that $\mathrm{C} 1 \mathrm{~V} \subseteq \mathrm{f}(\mathrm{C} 1 \mathrm{U})$. 
PROOF. Assume $\mathrm{f}: \mathrm{X} \rightarrow \mathrm{Y}$ is $\theta$-open. Let $\mathrm{x} \in \mathrm{X}$ and let $\mathrm{U}$ be an open neighborhood of $x$. Since $f(C 1 U)$ is a $\theta$-neighborhood of $f(x)$, there exists an open set $V$ such that $f(x) \varepsilon V \subseteq C 1 V \subseteq f(C 1 U)$.

Assume that for each $\mathrm{x} \varepsilon \mathrm{X}$ and each open neighborhood $U$ of $\mathrm{x}$ there exists an open neighborhood $V$ of $f(x)$ for which $C 1 V \subseteq f(C 1 U)$. Let $x \in X$ and let $N$ be a $\theta$-neighborhood of $x$. Then there is an open set $U$ for which $x \in U \subseteq C 1 U \subseteq N$. There exists an open set $V$ such that $f(x) \varepsilon V \subseteq C 1 V \subseteq f(C l U) \subseteq f(N)$. Hence $f(N)$ is a $\theta$-neighborhood of $f(x)$ and $f$ is $\theta$-open.

THEOREM 10. A function $\mathrm{f}: \mathrm{X} \rightarrow \mathrm{Y}$ is strongly $\theta$-open if and only if for each $X \varepsilon X$ and each open neighborhood $U$ of $x$, there exists an open neighborhood $V$ of $\mathrm{f}(\mathrm{x})$ such that $\mathrm{Cl} \mathrm{V} \subseteq \mathrm{f}(\mathrm{U})$.

THEOREM 11. A function $\mathrm{f}: \mathrm{X} \rightarrow \mathrm{Y}$ is almost strongly $\theta$-open if and only if for each $x \varepsilon X$ and each open neighborhood $U$ of $X$ there exists an open neighborhood $V$ of $\mathrm{f}(\mathrm{x})$ such that $\mathrm{Cl} \mathrm{V} \subseteq \mathrm{f}$ (Int $\mathrm{Cl} \mathrm{U})$.

THEOREM 12. A function $\mathrm{f}: \mathrm{X} \rightarrow \mathrm{Y}$ is weakly $\delta$-open if and only if for each $X \varepsilon X$ and each open neighborhood $U$ of $x$, there exists an open neighborhood $V$ of $\mathrm{f}(\mathrm{x})$ such that Int $\mathrm{C} 1 \mathrm{~V} \subseteq \mathrm{f}(\mathrm{C} 1 \mathrm{U})$.

We have the following implications: almost open $<=$ st. $\theta$-open $\Rightarrow$ almost st. $\theta$-open $\Rightarrow \theta$-open $\Rightarrow$ weak $\delta$-open $\Rightarrow$ weak open. The following examples show that these implications are not reversible.

EXAMPLE 1. Let $\mathrm{X}=\{\mathrm{a}, \mathrm{b}\}, \mathrm{T}_{1}=\{\mathrm{X}, \phi,\{\mathrm{a}\}\}, \mathrm{Y}=\{\mathrm{a}, \mathrm{b}, \mathrm{c}\}$, and $\mathrm{T}_{2}=\{\mathrm{Y}, \phi$, $\{a\}\{a, b\}\}$. The inclusion mapping: $\left.\left(X, T_{1}\right) \rightarrow Y, T_{2}\right)$ is weak open but not weak $\delta$-open.

In the next example the space $\left(Y, T_{2}\right)$ is from Example 2.2 in Noiri and Kang [9].

EXAMPLE 2. Let $\left(X, T_{1}\right)$ be as in Example 1. Let $Y=\{a, b, c, d\}$. and $\mathrm{T}_{2}=\{\mathrm{Y}, \phi\{\mathrm{a}\},\{\mathrm{c}\},\{\mathrm{a}, \mathrm{b}\},\{\mathrm{a}, \mathrm{c}\},\{\mathrm{a}, \mathrm{b}, \mathrm{c}\},\{\mathrm{a}, \mathrm{c}, \mathrm{d}\}\}$. The inclusion mapping: $\left(\mathrm{X}, \mathrm{T}_{1}\right) \rightarrow\left(\mathrm{Y}, \mathrm{T}_{2}\right)$ is weak $\delta$-open, but not $\theta$-open.

EXAMPLE 3. Let $\left(\mathrm{Y}, \mathrm{T}_{2}\right)$ be as in Example 2. The identity mapping: $\left(\mathrm{Y}, \mathrm{T}_{2}\right) \rightarrow$ $\left(\mathrm{Y}, \mathrm{T}_{2}\right)$ is $\theta$-open but not almost strongly $\theta$-open.

EXAMPLE 4. Let $\mathrm{X}=\{\mathrm{a}, \mathrm{b}, \mathrm{c}\}, \mathrm{T}_{1}=\{\mathrm{X}, \phi,\{\mathrm{a}\},\{\mathrm{a}, \mathrm{c}\}\}$ and $\mathrm{T}_{2}=\{\mathrm{X}, \phi,\{\mathrm{a}\}$, $\{c\},\{a, c\},\{a, b\}\}$. The identity mapping: $\left(X, T_{1}\right) \rightarrow\left(X, T_{2}\right)$ is almost strongly $\theta$-open and almost open, but not strongly $\theta$-open.

\section{REFERENCES}

1. LEVINE, Norman, A Decomposition of Continuity in Topological Spaces, Amer. Math. Monthly 68(1961) 44-46.

2. LONG, Paul E. and HERRINGTON, Larry L., Strongly $\theta$-Continuous Functions, J. Korean Math. Soc. 18(1981) 21-28.

3. NOIRI, Takashi, On $\delta$-Continuous Functions, J. Korean Math. Soc. 16(1980) 161-166.

4. ROSE, David A., Weak Continuity and Almost Continuity, Internat. J. Math. Math. Sci. 7(1984) 311-318.

5. ROSE, David A., Weak Openness and Almost Openness, Internat. J. Math. Math. Sc1. 7(1984) 35-40. 
6. SINGAL, M. K. and SINGAL, Asha Rani, Almost Continuos Mappings, Yokohama Math. J. $\underline{16}(1968) 63-73$.

7. VELICKO, N. V., H-Closed Topological Spaces, Amer. Math. Soc. Trans1. 78(1968) 103-118.

8. FOMIN, S., Extensions of Topological Spaces, Ann. Math. 44(1943) 471-480.

9. NOIRI, T. and KANG, Sin Min, On Almost Strongly $\theta$-Continuous Functions, Indian J. Pure App1. Math 15 (1984) 1-8.

10. BAKER, C. W., On Super-Continuous Functions, Bull. Korean Math. Soc., 22 (1985) 17-22. 


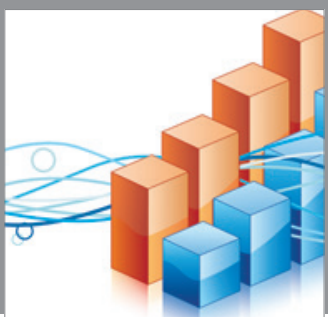

Advances in

Operations Research

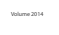

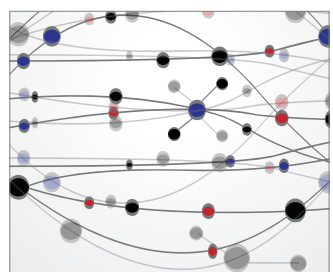

\section{The Scientific} World Journal
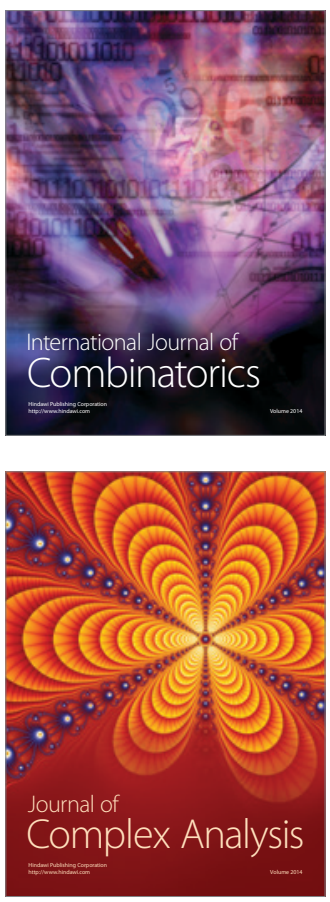

International Journal of

Mathematics and

Mathematical

Sciences
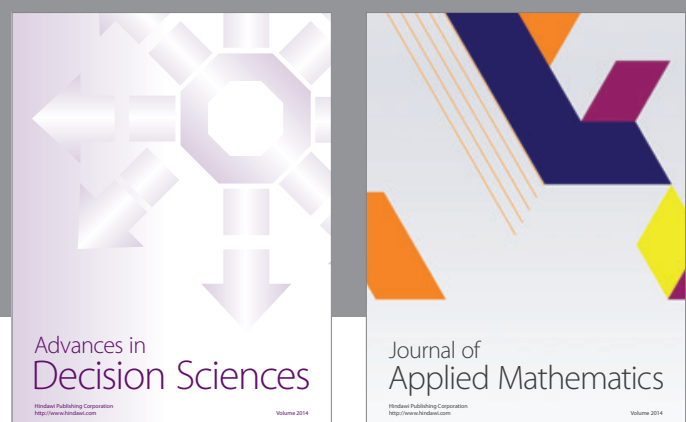

Journal of

Applied Mathematics
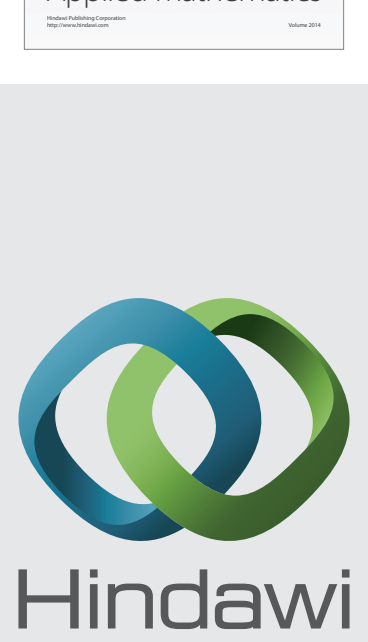

Submit your manuscripts at http://www.hindawi.com
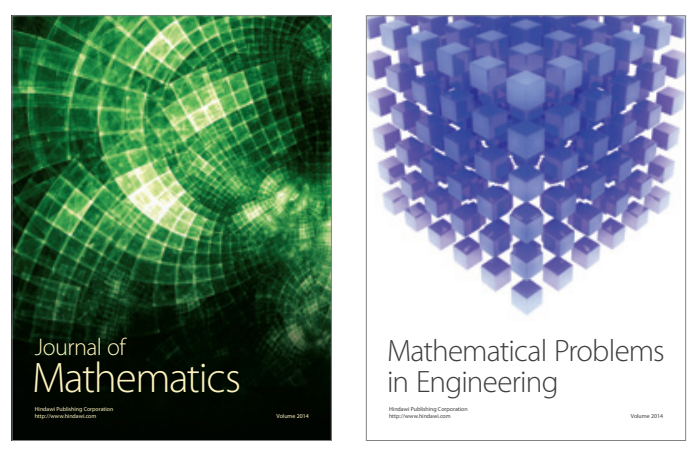

Mathematical Problems in Engineering
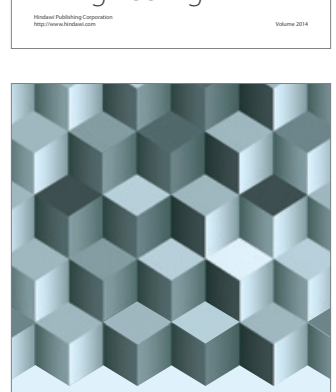

Journal of

Function Spaces
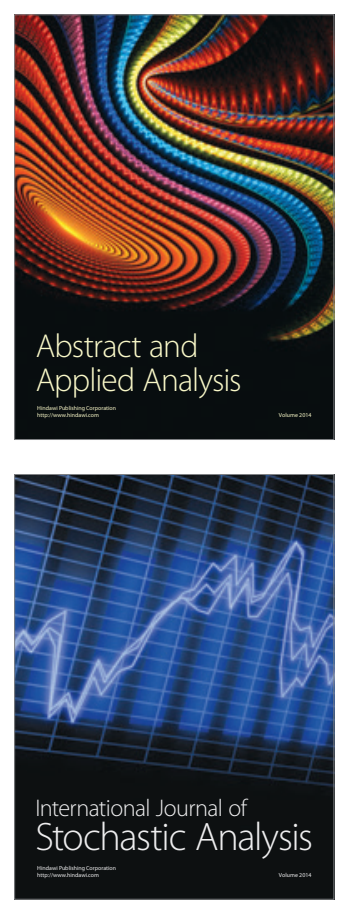

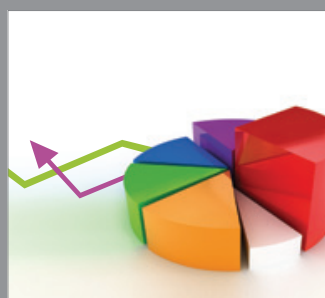

ournal of

Probability and Statistics

Promensencen
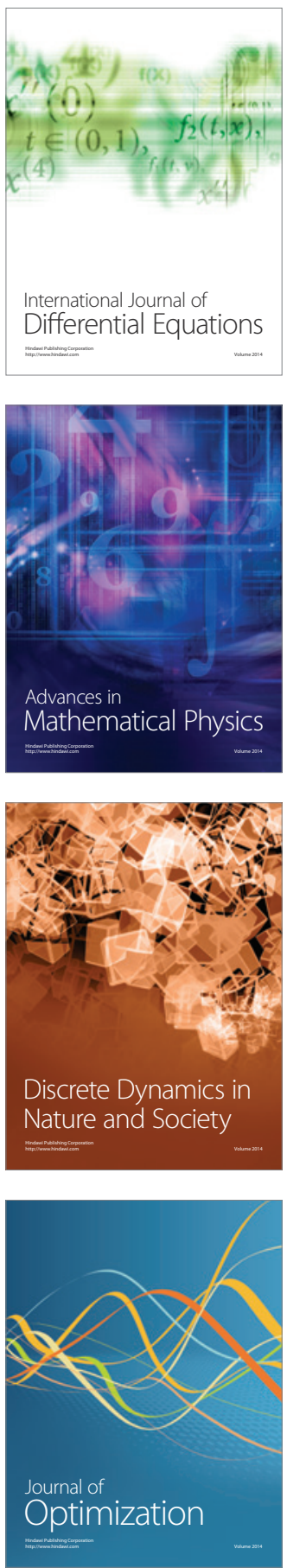